\title{
Glutathione-S-transferase (GST) P1, GSTM1, exercise, ozone and asthma incidence in school children
}

\author{
T Islam, K Berhane, R McConnell, W J Gauderman, E Avol, J M Peters, F D Gilliland
}

- Additional supplement published online only at http:// thorax.bmi.com/content/vol64/ issue3

Department of Preventive Medicine, Keck School of Medicine, University of Southern California Los Angeles, California, USA

Correspondence to: Dr F Gilliland, Department of Preventive Medicine, USC Keck School of Medicine, 1540 Alcazar Street, CHP 236, Los Angeles, CA 90033, USA; gillilan@usc.edu

Received 21 March 2008 Accepted 29 September 2008 Published Online First 6 November 2008

\begin{abstract}
Background: Because asthma has been associated with exercise and ozone exposure, an association likely mediated by oxidative stress, we hypothesised that glutathione-S-transferase (GST)P1, GSTM1, exercise and ozone exposure have interrelated effects on the pathogenesis of asthma.

Methods: Associations of the well characterised null variant of GSTM1 and four single nucleotide polymorphisms (SNPS) that characterised common variation in the GSTP1 locus with new onset asthma in a cohort of 1610 school children were examined. Children's exercise and ozone exposure were classified using participation in team sports and community annual average ozone levels, respectively.
\end{abstract}

Results: A two SNP model involving putatively functional variants (rs6591255, rs1695 (lle105Va)) best captured the association between GSTP1 and asthma. The risk of asthma was lower for those with the Val allele of lle105Val (hazard ratio (HR) $0.60,95 \% \mathrm{Cl} 0.4$ to 0.8 ) and higher for the variant allele of rs6591255 (HR 1.40, 95\% $\mathrm{Cl} 1.1$ to 1.9). The risk of asthma increased with level of exercise among ile ${ }^{105}$ homozygotes but not among those with at least one val ${ }^{105}$ allele (interaction $p$ value $=0.02$ ) The risk was highest among ile ${ }^{105}$ homozygotes who participated in $\geqslant 3$ sports in the high ozone communities (HR $6.15,95 \% \mathrm{Cl} 2.2$ to 7.4 ). GSTM1 null was independently associated with an increased risk of asthma and showed little variation with air pollution or GSTP1 genotype. These results were consistent in two independent fourth grade cohorts recruited in 1993 and 1996.

Conclusion: Children who inherit a val ${ }^{105}$ variant allele may be protected from the increased risk of asthma associated with exercise, especially in high ozone communities. GSTM1 null genotype was associated with an increased risk of asthma.

Airway oxidative stress is a cardinal feature and an important pathway in the pathogenesis of asthma. ${ }^{1}$ Although a growing body of evidence supports a joint role for air pollutants and variants in genes involved in oxidant defences in asthma pathogenesis, ${ }^{2}$ there have been few prospective studies of new onset asthma that have collected both the genetic and environmental data needed to address these determinants with adequate power. We addressed this gap by using data from the Children's Health Study (CHS), ${ }^{34}$ a longitudinal study of children's respiratory health. We have previously reported that children who exercise more in communities with high ozone levels are at increased risk of developing asthma. ${ }^{5}$ We have now investigated the impact of variants of oxidant defence genes in the context of these environmental and behavioural factors.

The lung has multiple antioxidative defences, including the superfamily of glutathione S-transferases (GSTs) ${ }^{6}$ that are essential for glutathione homeostasis ${ }^{7}$ and cytoprotection from the byproducts of oxidative stress. ${ }^{8}$ The GST superfamily includes a number of subclasses including GSTP1 and GSTM1 which are expressed in the lungs ${ }^{6}$ and have been implicated in the pathogenesis of asthma. ${ }^{9}$ The deletion allele of GSTM 1 (null genotype) has been associated with an increased risk of asthma and lower lung function. ${ }^{10}{ }^{11} \mathrm{~A}$ functional sequence variant in GSTP1 at codon 105 (Ile105Val- rs1695) ${ }^{12} 13$ has been associated with asthma in some $e^{11} 14-19$ but not all studies. ${ }^{20-22}$ This variant has been reported to be both protective $e^{14-1619}$ and a risk factor ${ }^{11} 11^{1823}$ for asthma. The inconsistency may have several explanations, including differences in asthma pathogenesis in young children and adults, as well as the effects of other common variants in GSTP1 coding and promoter regions or other GSTs, such as GSTM1. ${ }^{17} 18$

Environmental factors such as ambient ozone are also determinants of oxidative stress in the lungs. ${ }^{24}$ Because elevated ozone exposure is associated with an increased risk of new onset asthma in exercising children ${ }^{5}$ and GSTs are involved in the oxidative pathway, we hypothesised that the effects of genetic variants of GSTs on asthma are modified by children's participation in team sports in high and low ozone communities.

To investigate the joint effect of variants in GSTs (four single nucleotide polymorphisms (SNPs) of GSTP1 and GSTM1 null) and exercise on new onset asthma, we examined health, genetic and exposure data collected from Hispanic and non-Hispanic white children participating in the CHS. Our findings highlight the potential importance of genetic susceptibility, environmental exposure and behavioural factors in the aetiology of asthma.

\section{METHODS}

\section{Subjects and materials}

Children in this analysis participated in CHS cohorts that have been described previously. ${ }^{34}$ Each participant completed an annual self-administered questionnaire regarding sociodemographic, health and household characteristics and a brief exposure history to relevant asthma risk factors (further details of adjustment covariates are presented in the online supplement). This analysis 
Table 1 Selected characteristics of the study participants at study entry

\begin{tabular}{lc}
\hline & No (\%) (n= 1610) \\
\hline Hispanic & $546(33.9)$ \\
Age groups (years) & \\
$7-9$ & $861(53.5)$ \\
$10-11$ & $345(21.4)$ \\
$>11$ & $404(25.1)$ \\
Sex & \\
Girls & $893(55.5)$ \\
Boys & $717(44.5)$ \\
Overweight & $378(23.5)$ \\
Parental history of asthma & $221(13.7)$ \\
History of atopy & $384(25.3)$ \\
Household second hand smoke exposure & $235(14.6)$ \\
In utero exposure to maternal smoking & $220(13.7)$ \\
Current maternal smoking & $125(7.8)$ \\
Pests of any kind & $1213(75.3)$ \\
Pets at home & $1323(82.2)$ \\
No of team sports participation & \\
0 & $648(41.0)$ \\
1 & $536(33.9)$ \\
2 & $264(16.7)$ \\
Children with health insurance & $132(8.3)$ \\
Annual family income (US dollars) & $1323(82.2)$ \\
$\leqslant 14999$ & \\
15 000-49 999 & $177(11.0)$ \\
Highest parental education level* & $586(36.4)$ \\
Less than high school & $609(37.8)$ \\
College & $211(13.1)$ \\
Graduate & $1138(70.7)$ \\
\hline & $227(14.1)$ \\
\hline & \\
\hline &
\end{tabular}

*The numbers do not add up to the total due to missing data.

included 1610 children of Hispanic or non-Hispanic ethnicity who had no history of asthma or wheezing symptoms at study entry and who had GST genotype data (see online supplement).

\section{New onset asthma}

Children with no prior history of asthma or wheeze at study entry who subsequently reported physician diagnosed asthma at annual follow-up were classified as having new onset asthma.

\section{Ambient air pollution}

Outdoor levels of ozone $\left(\mathrm{O}_{3}\right)$, nitrogen dioxide $\left(\mathrm{NO}_{2}\right)$, particulate matter with an aerodynamic diameter of less than $10 \mu \mathrm{m}\left(\mathrm{PM}_{10}\right)$ or $2.5 \mu \mathrm{m}\left(\mathrm{PM}_{2.5}\right)$, acid vapour and elemental and organic carbon were measured continuously during the period of follow-up in each of the 12 communities at centrally located

Table 2 Pairwise measures of linkage disequilibrium $\left(r^{2}\right.$ and $\left.D^{\prime}\right)$ for the GSTP1 htSNPs

\begin{tabular}{lclll}
\hline $\mathbf{D}^{\prime} \backslash \mathbf{r}^{2}$ & $\begin{array}{l}\text { SNP1(T) } \\
(\mathbf{r s 6 5 9 1 2 5 5 )}\end{array}$ & $\begin{array}{l}\text { SNP2(C) } \\
(\mathbf{r s 4 1 4 7 5 8 1 )}\end{array}$ & $\begin{array}{l}\text { SNP3(A) } \\
(\mathbf{r s 1 6 9 5 )}\end{array}$ & $\begin{array}{l}\text { SNP4(C) } \\
(\mathbf{r s 7 4 9 1 7 4 )}\end{array}$ \\
\hline SNP1(T) & - & $\mathbf{0 . 4 9}$ & $\mathbf{0 . 3 6}$ & $\mathbf{0 . 6 3}$ \\
SNP2(C) & -0.99 & - & $\mathbf{0 . 4 3}$ & $\mathbf{0 . 3 2}$ \\
SNP3(105A) & 0.60 & -0.927 & - & $\mathbf{0 . 5 8}$ \\
SNP4(C) & 0.94 & -0.95 & 0.91 & - \\
\hline
\end{tabular}

$r^{2}$, upper triangle area (bold typeface). $D^{\prime}$, lower triangle area.

GST, glutathione-S-transferase; SNP, single nucleotide polymorphism. air monitoring sites. Average pollutant levels varied substantially across these communities; however, no substantial year to year variation was observed within communities. ${ }^{25}$ To assess the effects of ambient ozone on genetic susceptibility, we classified the community level exposure as low (range 28.6-45.5 ppb) or high (range 46.5-64.9 ppb) with six communities in each group, as described previously (see online supplement). ${ }^{5}$ Children's variation in dose of outdoor pollution was categorised using questionnaire responses about participation in team sports and pollution levels. Children were grouped into those who played no, one and two or more team sports.

\section{Other oxidative stress genes}

Based on previous findings in this cohort, we also considered the effect of a $(\mathrm{GT})_{\mathrm{n}}$ tandem repeat of the 5 flanking region of HMOX1 and a functional polymorphism of CAT (CAT262C > T: rs1001179) on GSTP1 and GSTM1 associations in our final models. ${ }^{26}$ As described previously, we categorised HMOX 1 alleles based on functional studies with 23 or less $(\mathrm{GT})_{\mathrm{n}}$ repeats as "short" $(\mathrm{S}){ }^{26}$

\section{Identifying haplotype tagging SNPs (htSNPs) of GSTP1}

Ethnic specific haplotype block structure for GSTP1 was identified by using Haploview V.3.3, which was based on genotype data for 71 Hispanic and 71 non-Hispanic whites from the well characterised Multi-Ethnic Cohort (see online supplement). ${ }^{27}$ The four htSNPs (rs6591255 (SNP1), rs4147581 (SNP2), Ile105Val (SNP3) and rs749174 (SNP4)) accounted for $>80 \%$ of the haplotype variation in the GSTP1 locus (see fig E2 online). Haplotype frequencies of unphased GSTP1 SNPs were estimated separately for Hispanic and non-Hispanic white subjects using TagSNPs (the program is available at http://www.hsc. usc.edu/ $\sim$ stram/).

\section{Statistical methods}

We fitted Cox proportional hazards models with sex and age specific (integer age at study entry) baseline hazards to investigate the association between the genetic variants and new onset asthma. An additive genetic model was used for each SNP. Because the associations of the variants were consistent in both Hispanic and non-Hispanic groups (see table E2 online) and the lowest $\mathrm{p}$ value for tests for ethnic heterogeneity was $>0.15$, the results are presented for the combined population. All models were adjusted for community and ethnicity.

To capture the joint effect of the four GSTP1 SNPs, we considered three different models: all four SNPs in a single model (joint model), two functional SNPs (functional model) and a haplotype model. The functional model included Ile $105 \mathrm{Val}$ and rs6591255 based on their functional effects. ${ }^{12} 1228$ We selected the best model based on the likelihood ratio tests (comparing "base" (without any genetic information) and "full" models (genetic information added to the base model)). Joint effect models for GSTP1 and GSTM1 were estimated similarly.

Additional covariates were considered for inclusion in the final model based on whether their inclusion changed the effect estimates of the genetic variants by more than 10\%. Possible heterogeneity of association by participation in team sports or GSTM1 status was assessed by comparing appropriate models with and without appropriate interaction terms. In the presence of statistically significant heterogeneity among subgroups, a stratified analysis was performed. 
Table 3 Associations between GSTP1 and GSTM1 genotypes and haplotypes with new onset asthma

\begin{tabular}{|c|c|c|c|c|}
\hline Model & $\begin{array}{l}\text { Genotype and } \\
\text { haplotype } \dagger\end{array}$ & $\begin{array}{l}\text { No (with } \\
\text { asthma/without } \\
\text { asthma) }\end{array}$ & HR $(95 \% \mathrm{Cl}) *$ & p Value§ \\
\hline \multicolumn{5}{|l|}{ GSTP1 } \\
\hline \multirow[t]{4}{*}{ Joint } & SNP1(A) & $150 / 1474$ & 1.23 (0.8 to 1.9$)$ & 0.03 \\
\hline & SNP2(G) & & 0.85 (0.6 to 1.2$)$ & \\
\hline & $\mathrm{SNP} 3(\mathrm{G})$ & & $0.54(0.3$ to 0.9$) \uparrow$ & \\
\hline & SNP4(T) & & $1.10(0.6$ to 1.9$)$ & \\
\hline \multirow{2}{*}{ Functional } & SNP1(A) & $150 / 1493$ & 1.40 (1.1 to 1.9$) \uparrow$ & 0.007 \\
\hline & SNP3(G) & & $0.60(0.4 \text { to } 0.8)^{* *}$ & \\
\hline \multirow[t]{6}{*}{ Haplotype: } & TCAC & $150 / 1474$ & 1 (Ref) & 0.14 \\
\hline & ACAC & & 1.33 (0.8 to 2.2 ) & \\
\hline & TGAC & & $0.90(0.6$ to 1.4$)$ & \\
\hline & TCGC & & $0.64(0.3$ to 1.2$)$ & \\
\hline & ACGT & & $0.76(0.5$ to 1.2$)$ & \\
\hline & Other & & $0.97(0.5$ to 1.9$)$ & \\
\hline GSTM1 & Null & $152 / 1472$ & $1.61(1.2 \text { to } 2.2)^{* *}$ & 0.004 \\
\hline \multicolumn{5}{|c|}{ Joint GSTM1 and GSTP1 model } \\
\hline \multirow[t]{2}{*}{ GSTP1 } & SNP1(A) & $144 / 1453$ & 1.45 (1.1 to 1.9$) \uparrow$ & $0.007 \dagger \dagger$ \\
\hline & $\mathrm{SNP} 3(\mathrm{G})$ & & $0.61(0.4 \text { to } 0.8)^{* *}$ & \\
\hline GSTM1 & Null & & $1.52(1.1$ to 2.1$)$ & \\
\hline \multicolumn{5}{|c|}{$\begin{array}{l}\text { *Hazard ratio (HR) and } 95 \% \mathrm{Cl} \text { adjusted for community of residence and ethnicity. Additive genetic coding was used for all SNPs. } \\
\dagger \text { The letter in parentheses represents the variant allele. } \\
\text { \$The sequence of the GSTP1 haplotype is SNP1-SNP2-SNP3-SNP4. Haplotypes with less than } 5 \% \text { frequency in both the ethnic } \\
\text { groups were summarised as "Other". } \\
\text { §The p value is derived from the LRT. The LRT was calculated by comparing models with and without the corresponding genetic } \\
\text { data. } \\
\text { Tp value }<0.05 ; \text { * *p value }<0.001 \text {. } \\
\text { ††This LRT P value was calculated by comparing a model with SNP1 and SNP3 of GSTP1and GSTM1 "null" to one with only } \\
\text { GSTM1 "null". All models were adjusted for ethnicity and community of residence. } \\
\text { GST, glutathione-S-transferase; LRT, likelihood ratio test; SNP, single nucleotide polymorphism. }\end{array}$} \\
\hline
\end{tabular}

To assess the effect of ambient ozone on the relationship between genetic variation in GSTP1 and new onset asthma and account for the clustering effect of children in communities, we fitted a Cox proportional hazards model to these time dependent data with random effects for the communities (see online supplement). ${ }^{29}$ In these models, the community specific average ozone levels were fitted as continuous variables along with the appropriate interaction terms for participation in team sports, genotype and ozone level. To allow more easily interpretable estimates of the effect of participation of team sports and genotype on risk of new onset asthma, we also performed stratified analysis using Cox proportional hazards models in communities with higher/lower levels of ambient ozone.

All analyses, except the hierarchical two stage model, were conducted using SAS software V.9.1 (SAS Institute, North Carolina, USA). The hierarchical two stage model was fitted using the R-program's COXP procedure. ${ }^{29}$ All hypothesis testing was conducted assuming a 0.05 significance level and a two sided alternative hypothesis.

\section{RESULTS}

\section{Participant characteristics}

The majority of the children included in this analysis were less than 10 years of age and non-Hispanic white (table 1). Distributions for some sociodemographic and environmental factors at study entry differed between Hispanic and nonHispanic white children (see online supplement and table E3 online). However, the crude incidence rate of asthma did not differ between non-Hispanic white children (IR $=16.1 / 1000$ person-year) and Hispanic children (IR $=16.6 / 1000$ personyear). There were some modest differences in baseline characteristics between children with and without genetic data (see table E4 online).

\section{Allele frequencies}

All GSTP1 SNPs were in Hardy-Weinberg equilibrium in both ethnic groups. The distribution of the GSTP1 alleles was similar for both ethnic groups except for SNP2 (see table E5 in the online supplement). Except for SNP1 and SNP3 (Ile105Val), all SNPs showed moderate to high degrees of linkage disequilibrium -with each other (table 2 and see online supplement results).

\section{Associations of GSTP1 and GSTM1 with new onset asthma}

The two functional variants of GSTP1 (SNP1 and SNP3) best defined the association between GSTP1 and new onset asthma (table 3). In this "functional" SNP model, the risk of asthma decreased by $40 \%$ (hazard ratio (HR) $0.60,95 \%$ CI 0.4 to 0.8 ) among children with SNP3 "G" (val ${ }^{105}$ ) and increased by $40 \%$ among children with SNP1 variant allele (A) (HR 1.40, 95\% CI 1.1 to 1.9). This pattern is consistent with the haplotype analysis where reduced risk of asthma was observed for TCGC and ACGT (HR 0.64 and 0.76) and increased risk of asthma for ACAC (HR 1.33) compared with the TCAC haplotype.

Children who had the GSTM1 null genotype were at 1.6-fold (95\% CI 1.2 to 2.2 ) increased risk of developing new onset asthma compared with those without the null genotype (table 3). The point estimates for asthma risk for GSTP1 SNPs were similar among children with and without the GSTM1 null genotype (see table E7 online).

These associations were not substantially affected by adjustment for possible confounders (see online table E8 model 1) and ambient pollutants (see online table E8: models 2 and 3). To 
Table 4 Associations of GSTP1 genotypes with new onset asthma, stratified by participation in team sports* $^{*}$

\begin{tabular}{|c|c|c|c|c|c|}
\hline \multirow[b]{2}{*}{$\begin{array}{l}\text { No of sports } \\
\text { played } \dagger\end{array}$} & \multicolumn{4}{|l|}{ GSTP1 genotype } & \multirow[b]{2}{*}{$\begin{array}{l}\text { Interaction } \\
\text { p value§ }\end{array}$} \\
\hline & $\begin{array}{l}\text { No (with } \\
\text { asthma/without } \\
\text { asthma) }\end{array}$ & HR $(95 \%$ CI) & $\begin{array}{l}\text { No (with } \\
\text { asthma/without } \\
\text { asthma) }\end{array}$ & HR $(95 \% \mathrm{CI})$ & \\
\hline & \multicolumn{5}{|l|}{ SNP3 (/le105Val) } \\
\hline & \multicolumn{2}{|l|}{ Ile/Ile } & \multicolumn{2}{|l|}{ Ile/Val or $\mathrm{Val} / \mathrm{Val}$} & \\
\hline None & $21 / 226$ & 1 (Ref) & $36 / 365$ & $0.90(0.5$ to 1.6$)$ & 0.02 \\
\hline $1-2$ & $37 / 286$ & $1.42(0.8$ to 2.5$)$ & $33 / 444$ & $0.73(0.4$ to 1.3$)$ & \\
\hline$>2$ & $10 / 46$ & $2.66(1.2$ to 5.9$)$ - & $5 / 71$ & 0.68 (0.2 to 1.9$)$ & \\
\hline \multirow[t]{3}{*}{ p Value: } & & 0.03 & & 0.41 & \\
\hline & \multicolumn{3}{|c|}{ SNP1 (rs6591255 A>T) } & & \\
\hline & $\mathrm{AA}$ & & $\mathrm{AT} / \mathrm{TT}$ & & \\
\hline None & $20 / 254$ & 1 (Ref) & $37 / 337$ & $1.92(1.1$ to 3.5$)$ & 0.08 \\
\hline $1-2$ & $26 / 282$ & 1.17 (0.6 to 2.1$)$ & $44 / 448$ & 1.87 (1.0 to 3.4$)$ & \\
\hline$>2$ & $9 / 48$ & $2.49(1.1$ to 5.7$)$ & $6 / 69$ & $1.84(0.7$ to 4.8$)$ & \\
\hline p Value: & & 0.07 & & 0.81 & \\
\hline $\begin{array}{l}{ }^{*} \text { All models } \\
\dagger \text { Children we } \\
\text { †A test for a } \\
\text { participation) } \\
\text { §Interaction p } \\
\text { sport categor } \\
\text { Tp value }<0 \text {. } \\
\text { GST, glutathi }\end{array}$ & $\begin{array}{l}\text { adjusted for ethnici } \\
\text { sategorised by the } \\
\text { nd was performed } \\
\text { base models stratif } \\
\text { lue was calculated } \\
\text { nd SNP) to the bas }\end{array}$ & $\begin{array}{l}\text { ommunity of reside } \\
\text { oer of team sports } \\
\text { the likelihood ratio } \\
\text { lle1905Val status } \\
\text { likelihood ratio tes } \\
\text { ain effect of sports }\end{array}$ & $\begin{array}{l}\text { GSTM1 and SNP1/ } \\
\text { d. } \\
\text { comparing full (du } \\
\text { nparing full (main e } \\
\text { SNP only) models. } \\
\text { hism. }\end{array}$ & $\begin{array}{l}\text { variables for } 1,2 \\
\text { of sports, SNP and }\end{array}$ & araction term for \\
\hline
\end{tabular}

assess the potential effects of asthma misclassification, we restricted the case definition of new onset asthma to those using inhaled medication and found no substantial differences in the magnitude of risk associated with the genetic variants (see online table E8 model 4). In both ethnic specific (data not shown) and combined analyses (see online table E8 model 5), the estimates of risk for the GST polymorphisms remained essentially unchanged after adjustment for HMOX1 and CAT genotypes.

\section{GSTP1, team sports and ozone}

The effect of SNP3 (Ile105 Val) on new onset asthma differed by participation in team sports (table 4 , interaction $p$ value $=0.02$ ), after adjustment for SNP1 and GSTM1 status. Children without a protective $v^{105}$ allele showed an increased risk for new onset asthma with increasing participation in team sports ( $p$ trend $=0.03$ ). In contrast, the number of team sports was unrelated to asthma risk for children with a val ${ }^{105}$ allele (table 4, $p$ trend $=0.41$ ). An increased risk of asthma associated with the variant allele "A" of SNP1 was observed among children, independent of participation in team sports. Among children without the variant allele of SNP1, an increased risk for asthma was observed for those who played three or more team sports (HR 2.49, 95\% CI 1.1 to 5.7). Unlike the GSTP1 SNPs, the association between GSTM1 and new onset asthma did not vary by team sports participation.

Although sample size was limited, we investigated the joint effects of GSTP1 genotype and sport participation in high and low ozone communities (table 5). A sixfold elevated risk of asthma (HR 6.15, 95\% CI 2.2 to 7.4) in children who played $>2$ team sports and were $I l e^{105}$ homozygotes was observed in the high ozone communities.

\section{DISCUSSION}

We observed that functional variants of both GSTP1 and GSTM1 were associated with new onset asthma during adolescence. In addition to the well studied vallos variant, we found that a potentially functional SNP of GSTP1, located in the promoter region, was also associated with asthma and these two functional SNPs best explained the association between the GSTP1 gene and new onset asthma during adolescence. Furthermore, the associated risk of new onset asthma among participants playing multiple team sports ${ }^{5}$ also depended upon a child's Ile105Val genotype. Playing multiple team sports was

Table 5 Joint associations of GSTP1 lle105Val* genotype and participation in team sports on the risk of new onset asthma among CHS participants residing in high and low ozone communities

\begin{tabular}{|c|c|c|c|c|c|c|c|c|}
\hline \multirow{3}{*}{$\begin{array}{l}\text { No of sports } \\
\text { played }\end{array}$} & \multicolumn{4}{|c|}{ Low ozone communities $(n=6) \dagger$} & \multicolumn{4}{|c|}{ High ozone communities $(n=6) \dagger$} \\
\hline & \multicolumn{2}{|l|}{ IIe/IIe } & \multicolumn{2}{|c|}{ Ile/Val or $\mathrm{Val} / \mathrm{Val}$} & \multicolumn{2}{|l|}{ Ile/Ile } & \multicolumn{2}{|c|}{ Ile/Val or Val/Val } \\
\hline & No: & HR $(95 \% \mathrm{CI})$ & No & HR $(95 \% \mathrm{CI})$ & No & HR (95\% CI) & No & HR (95\% CI) \\
\hline None & $10 / 93$ & 1 (Ref) & 20/181 & $0.86(0.4$ to 1.9$)$ & $11 / 133$ & 1 (Ref) & $16 / 184$ & $0.98(0.4$ to 2.3$)$ \\
\hline $1-2$ & $21 / 142$ & $1.37(0.6$ to 3.0$)$ & $19 / 205$ & $0.69(0.3$ to 1.6$)$ & $16 / 144$ & $1.37(0.6$ to 3.1$)$ & $14 / 239$ & $0.80(0.3$ to 1.9$)$ \\
\hline$>2$ & $3 / 28$ & $1.06(0.3$ to 4.0$)$ & $2 / 38$ & $0.50(0.1$ to 2.4$)$ & $7 / 18$ & $6.15(2.2$ to 7.4$) \S$ & $3 / 33$ & $1.06(0.3$ to 4.1$)$ \\
\hline
\end{tabular}

*All models are adjusted for ethnicity, community of residence, GSTM1 and SNP1. The effect of SNP3 was treated as "additive". $\dagger$ High and low ozone communities were defined according to average 10:00 to 06:00 ozone levels. The ozone levels (10:00 to 06:00) ranged from 46.5 to $64.9 \mathrm{ppb}$ in the "high" ozone communities (mean $38.4 \mathrm{ppb}$ ) and from 28.6 to $45.5 \mathrm{ppb}$ in the "low" ozone communities (mean $55.2 \mathrm{ppb}$ ).

Children with and without asthma.

§p value $<0.05$.

GST, glutathione-S-transferase; SNP, single nucleotide polymorphism. 
associated with an increased risk of asthma only among children who were homozygous for $I l e^{105}$, and the risk in this group was highest for those living in the high ozone communities. These observations reflect the complex interrelationship of asthma risk with increasing doses of ozone (resulting from increasing ventilation associated with vigorous exercise) and antioxidant defences.

Our findings are supported by the growing body of evidence for gene-pollution interaction in the pathogenesis of asthma. ${ }^{2}$ GSTM1 and GSTP1 are two important phase II enzymes that protect the airways from oxidative stress. ${ }^{8}$ Oxidative stress has been shown to be central to asthma pathogenesis. ${ }^{30}$ Therefore, genetic variants that regulate the availability and functionality of the GST enzymes are expected to determine the dose of oxidative effects in the airway and associated injury. Individuals with the GSTM1 null genotype completely lack GSTM1 enzyme activity and their increased susceptibility to asthma has been previously reported. ${ }^{11}{ }^{31}$ Furthermore, in the CHS we have observed that the null genotype is associated with reduced lung function growth during adolescence. ${ }^{10}$ In cross sectional analysis of childhood asthma, we observed that in utero exposure to maternal smoking was associated with increased risk of asthma/wheeze only among carriers of the GSTM1 null genotype. ${ }^{32}$ In this current prospective analysis, we found that GSTM1 is a determinant of asthma risk during adolescence, irrespective of in utero exposure to maternal smoking. Thus the detrimental effect of the GSTM1 null genotype on respiratory health is apparent from early childhood into adolescence.

In cross sectional analysis of this cohort, ${ }^{23}$ we also observed that a joint effects model of SNP1 and SNP3 best explained the association between GSTP1 and asthma during early childhood. The variant "A" allele of SNP1 corresponds to a haplotype of the promoter region that is associated with reduced GSTP1 activity $^{28}$ and thus the association with increased risk of asthma is biologically plausible. The observed association is consistent with our earlier observation of associations between SNP1 and early and late onset asthma. ${ }^{23}$

Our finding that the val ${ }^{105}$ confers protection against new onset asthma is consistent with most of the previous publications ${ }^{14-16} 193^{33}$ 34 however, increased risk ${ }^{11} 171823$ and no association $^{20-22} 3133$ have also been reported (see fig E3 online). We have previously reported that val ${ }^{105}$ is associated with an increased risk of early onset asthma (diagnosis by 3 years of age) but not with asthma onset after 3 years of age. ${ }^{23}$ Differences in the aetiology of asthma by age of onset ${ }^{35}$ and atopic status ${ }^{18}$ have been postulated as a possible explanation for the observed discrepancies across studies and both of these factors are possible explanations for the observed differences in asthmaval $^{105}$ association in CHS. Although atopy is one aetiological factor whose contribution to asthma varies by age, we did not observe a difference in effect of the Ile105 Val variant by atopy status, suggesting that the mechanism for the hypothesised age dependent pattern of risk associated with the vallos variant is likely to be more complex. Further research is needed to characterise the age dependent effects of the val ${ }^{105}$ on the development of asthma and to determine the mechanism for any age dependent differences in risk.

We previously reported that the risk of new onset asthma was associated with heavy outdoor exercise, especially in high ozone communities. ${ }^{5}$ The plausibility of a causal association is further strengthened by the observation that the risk of participation in team sports was related to increased genetic susceptibility to oxidative stress. The observed sixfold increased risk of asthma for children who were homozygous for $\mathrm{Ile}^{105}$, participated in $\geqslant 3$ team sports and lived in high ozone communities demonstrates the potential importance of a combination of genetic variability, environmental ozone exposure and behaviour on asthma risk. A modifying role of air pollution on the association between Ile105 Val and asthma has also been reported from a study involving South Korean children. ${ }^{15}$

The strengths of our study originate from the prospective assessment of asthma and air pollution among a large population based sample of children. Potential limitations include selection bias, confounding by admixture and outcome misclassification. We considered the potential effects of selection bias, as genetic data were available from about two-thirds of the initial cohort. Demographic and socioeconomic factors, exposure to maternal smoking during pregnancy and second hand smoke after birth, and household factors showed modest differences between participants and non-participants (see table E4 of the online supplement). Adjustment for these factors did not explain our results (see table E8 model 1 online), indicating that selection bias is unlikely to explain our results.

Population admixture is also an unlikely explanation for our findings as the incidence rate of new onset asthma did not vary by ethnicity and the associations of the SNPs were similar in ethnic specific analysis (see table E2 online). In both Hispanic and non-Hispanic whites, the distribution (see table E5 online), linkage disequilibrium structure (see table E6 online) and association with asthma (see table E2 online) of the GSTP1 SNPs were largely consistent. The GSTM1 "null" genotype and both GSTP1 SNPs in the "functional" model showed a similar pattern (SNP1 increased the risk and SNP3 decreased the risk of asthma) in both ethnic groups (see table E2 online). In the "joint effect" model, the HRs for all four GSTP1 SNPs showed little differences between ethnic groups except for SNP1. However, the CIs were wide and the estimates are not statistically significantly different (interaction $p$ value $>0.15$ ) and should not be over interpreted. We used joint models of the identified functional GSTP1 model and GSTM1 throughout our analysis. Furthermore, the four SNPs of GSTP1 captured $>80 \%$ of the variability of the GSTP1 locus.

Our findings are also unlikely to be due to asthma misclassification as we excluded children with any history of wheeze/asthma at study entry, and the observed risk estimates were largely unchanged when we restricted our analysis to asthma cases with inhaler use (see discussion in the online supplement). Another potential concern is that the results were a result of chance. However, both SNP1 and SNP3 were identified a priori for the joint genetic models, based on the known functional effect of these SNPs, as well as our previous findings from cross sectional analysis of childhood asthma. ${ }^{23}$ The GST associations were independent of HMOX1 and CAT (see table E8 model 5 online) that are involved in the antioxidative pathway and have been shown to be associated with new onset asthma. Furthermore, to confirm our finding, we performed separate analyses for the two fourth grade cohorts in our study population independently recruited in 1993 and 1996 and the seventh and tenth grade cohort (see table E9 online). The genetic effect estimates for each of these cohorts were consistent across these groups.

We conclude that common functional variants of GSTP1 and GSTM1 null genotype modulate the risk of new onset asthma during adolescence. The role of regulation of expression and variation of the function of GSTP1 in asthma pathogenesis needs further investigation, especially in the context of oxidative stress and age of diagnosis. Furthermore, the GSTP1-Ile105Val 
may also influence asthma susceptibility for adolescents who participate in sports in communities with elevated ozone levels. These findings suggest that the regulatory policy for ozone level may need to consider GSTP1 genotypes to set standards that protect the most vulnerable members of our societies.

Acknowledgements: We acknowledge all the participants of the CHS study and their parents, as well as all the teachers and staff of the participating schools. Without their active participation we would not have been able to address these intriguing and important aspects of respiratory health in children and adolescents. We also thank our colleagues who were involved in the collection, maintenance and quality control of the database as well as the Multi-Ethnic Cohort for contributing DNA samples used for selecting tagging SNP.

Funding: This work was supported by the Southern California Environmental Health Sciences Center (grant No 5P30ES007048) funded by the National Institute of Environmental Health Sciences; the Children's Environmental Health Center (grant Nos 5P01ES009581, R826708-01 and RD831861-01) funded by the National Institute of Environmental Health Sciences and the Environmental Protection Agency; the National Institute of Environmental Health Sciences (grant No 5P01ES011627); the National Heart, Lung and Blood Institute (grant Nos 5R01HL061768 and 5R01HL076647); and the Hastings Foundation.

Competing interests: None.

Ethics approval: Ethics approval was obtained.

\section{REFERENCES}

1. Greene LS. Asthma and oxidant stress: Nutritional, environmental, and genetic risk factors. J Am Coll Nutr 1995;14:317-24.

2. London SJ. Gene-air pollution interactions in asthma. Proc Am Thorac Soc 2007:4:217-20.

3. Peters JM, Avol E, Gauderman WJ, et al. A study of twelve southern california communities with differing levels and types of air pollution. li. Effects on pulmonary function. Am J Respir Crit Care Med 1999;159:768-75.

4. Peters JM, Avol E, Navidi W, et al. A study of twelve Southern California communities with differing levels and types of air pollution. I. Prevalence of respiratory morbidity. Am J Respir Crit Care Med 1999;159:760-7.

5. McConnell R, Berhane K, Gilliland F, et al. Asthma in exercising children exposed to ozone: A cohort study. Lancet 2002;359:386-91.

6. Rahman I, Biswas SK and Kode A. Oxidant and antioxidant balance in the airways and airway diseases. Eur J Pharmacol 2006;533:222-39.

7. Hayes JD, McLellan LI. Glutathione and glutathione-dependent enzymes represent a co-ordinately regulated defence against oxidative stress. Free Radic Res 1999;31:273-300.

8. Hayes JD, Flanagan JU, Jowsey IR. Glutathione transferases. Annu Rev Pharmacol Toxicol 2005; 45:51-88.

9. Strange RC, Spiteri MA, Ramachandran S, et al. Glutathione-s-transferase family of enzymes. Mutat Res 2001;482:21-6.

10. Gilliland FD, Gauderman WJ, Vora H, et al. Effects of glutathione-s-transferase $\mathrm{m1}$, $\mathrm{t} 1$, and $\mathrm{p} 1$ on childhood lung function growth. Am J Respir Crit Care Med 2002;166:710-16.

11. Tamer L, Calikoglu M, Ates NA, et al. Glutathione-s-transferase gene polymorphisms (gstt1, gstm1, gstp1) as increased risk factors for asthma. Respirology 2004;9:493-8.

12. Sundberg K, Johansson AS, Stenberg G, et al. Differences in the catalytic efficiencies of allelic variants of glutathione transferase p1-1 towards carcinogenic diol epoxides of polycyclic aromatic hydrocarbons. Carcinogenesis 1998;19:433-6.
13. Hu X, Xia H, Srivastava SK, et al. Activity of four allelic forms of glutathione stransferase hgstp1-1 for diol epoxides of polycyclic aromatic hydrocarbons. Biochem Biophys Res Commun 1997;238:397-402.

14. Fryer AA, Bianco A, Hepple $\mathrm{M}$, et al. Polymorphism at the glutathione s-transferase gstp1 locus. A new marker for bronchial hyperresponsiveness and asthma. Am J Respir Crit Care Med 2000;161:1437-42.

15. Lee $\mathrm{YL}$, Lin $\mathrm{YC}$, Lee $\mathrm{YC}$, et al. Glutathione s-transferase $\mathrm{p} 1$ gene polymorphism and air pollution as interactive risk factors for childhood asthma. Clin Exp Allergy 2004:34:1707-13

16. Mapp CE, Fryer AA, De Marzo N, et al. Glutathione s-transferase gstp1 is a susceptibility gene for occupational asthma induced by isocyanates. J Allergy Clin Immunol 2002;109:867-72.

17. Lee YL, Hsiue TR, Lee YC, et al. The association between glutathione s-transferase $\mathrm{p} 1, \mathrm{~m} 1$ polymorphisms and asthma in taiwanese schoolchildren. Chest 2005; 128:1156-62.

18. Kamada $\mathbf{F}$, Mashimo $Y$, Inoue $H$, et al. The gstp1 gene is a susceptibility gene for childhood asthma and the gstm1 gene is a modifier of the gstp1 gene. Int Arch Allergy Immunol 2007;144:275-86.

19. Aynacioglu AS, Nacak M, Filiz A, et al. Protective role of glutathione s-transferase p1 (gstp1) val105val genotype in patients with bronchial asthma. Br J Clin Pharmacol 2004;57:213-17.

20. Brasch-Andersen C, Christiansen L, Tan Q, et al. Possible gene dosage effect of glutathione-s-transferases on atopic asthma: Using real-time pcr for quantification of gstm1 and gstt1 gene copy numbers. Hum Mutat 2004;24:208-14.

21. Nickel R, Haider A, Sengler C, et al. Association study of glutathione s-transferase p1 (gstp1) with asthma and bronchial hyper-responsiveness in two german pediatric populations. Pediatr Allergy Immunol 2005;16:539-41.

22. Mak JC, Ho SP, Leung HC, et al. Relationship between glutathione s-transferase gene polymorphisms and enzyme activity in hong kong chinese asthmatics. Clin Exp Allergy 2007;37:1150-7.

23. Li YF, Gauderman WJ, Conti DV, et al. Glutathione s-transferase p1, maternal smoking, and asthma in children: A haplotype-based analysis. Environ Health Perspect 2008;116:409-15.

24. Mustafa MG. Biochemical basis of ozone toxicity. Free Radic Biol Med 1990;9:245-65.

25. Gauderman WJ, Avol E, Gilliland F, et al. The effect of air pollution on lung development from 10 to 18 years of age. N Engl J Med 2004;351:1057-67.

26. Islam T, McConnell R, Gauderman WJ, et al. Ozone, oxidant defense genes, and risk of asthma during adolescence. Am J Respir Crit Care Med 2008;177:388-95.

27. Kolonel LN, Henderson BE, Hankin JH, et al. A multiethnic cohort in Hawaii and Los Angeles: Baseline characteristics. Am J Epidemiol 2000;151:346-57.

28. Cauchi S, Han W, Kumar SV, et al. Haplotype-environment interactions that regulate the human glutathione s-transferase p1 promoter. Cancer Res 2006;66:6439-48.

29. Ma R, Krewski D and Burnett RT. Random effects cox models: A poisson modeling approach. Biometrika 2003;90:157-69.

30. Ercan H, Birben E, Dizdar EA, et al. Oxidative stress and genetic and epidemiologic determinants of oxidant injury in childhood asthma. J Allergy Clin Immunol 2006;118:1097-104.

31. Hanene C, Jihene L, Jamel A, et al. Association of gst genes polymorphisms with asthma in Tunisian children. Mediators Inflamm 2007;2007:19564.

32. Gilliland FD, Li YF, Gong $\mathrm{H} \mathrm{Jr}$, et al. Glutathione s-transferases $\mathrm{m} 1$ and $\mathrm{p} 1$ prevent aggravation of allergic responses by secondhand smoke. Am J Respir Crit Care Med 2006; 174:1335-41.

33. Hemmingsen $\mathbf{A}$, Fryer $\mathrm{AA}$, Hepple $\mathrm{M}$, et al. Simultaneous identification of gstp1 ile105-->val105 and ala114-->val114 substitutions using an amplification refractory mutation system polymerase chain reaction assay: Studies in patients with asthma. Respir Res 2001;2:255-60.

34. Imboden M, Rochat T, Brutsche MH, et al. Glutathione-s transferase genotype increases risk of progression from bronchial hyperresponsiveness to asthma in adults. Thorax 2008;63:322-8.

35. Lenney W, Fryer AA. The genetics of asthma: Are the glutathione s-transferases serious players? Clin Exp Allergy 2007;37:1124-6. 